\title{
Percepção e enativismo em \\ Merleau-Ponty e Francisco Varela
}

\section{Perception and enactivism in Merleau-Ponty and Francisco Varela}

DOI: $10.12957 /$ ek.2018.36228

\author{
Dndo. Rodrigo Benevides Barbosa Gomes \\ rodrigobenevides23@gmail.com \\ Universidade Federal de São Carlos
}

A percepção, argumenta Merleau-Ponty, deve ser entendida menos como uma representação de inputs desassociados e mais como uma apreensão corporal irrefletida de Gestalten. Tal formulação encontra continuidade no contexto das ciências cognitivas na crítica ao representacionismo efetivada pelo paradigma do enativismo, assim formulado por Francisco Varela, Evan Thompson e Eleanor Rosche em Embodied Mind: Cognitive Science and Human Experience (1991). Demonstrar e examinar a abordagem enativista, apontando sua harmonia com a fenomenologia de Merleau-Ponty, constitui o objetivo do presente artigo.

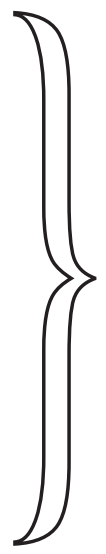

PALAVRAS-CHAVE Merleau-Ponty. Francisco Varela. Percepção. Enativismo

Perception, Merleau-Ponty argues, must be understood less as a representation of disassociated inputs and more as an unreflected bodily apprehension of Gestalten. Such thesis finds continuity in the context of cognitive sciences on the critique of representationalism of the enactivist paradigm, formulated by Francisco Varela, Evan Thompson e Eleanor Rosche in Embodied Mind: Cognitive Science and Human Experience (1991). To demonstrate and examine the enactive approach, pointing out its confluence with MerleauPonty's phenomenology, is the goal of the article.

KEY-WORDS Merleau-Ponty. Francisco Varela. Perception. Enactivism 


\section{Introdução}

Merleau-Ponty afirma que "a percepção originária é uma experiência não-tética, pré-objetiva e pré-consciente" (1999, p. 325), ou seja, defende-se na Fenomenologia da percepção (1945) a existência de uma intencionalidade corporal que opera abaixo do fluxo de consciência. Ao destacar o papel da corporeidade, Merleau-Ponty distancia-se de formulações da consciência restritas ao cérebro, uma posição comum tanto ao cientista cognitivo quanto ao leigo: "O senso comum põe o lugar do pensamento na cabeça" (1999, p. 202). A perspectiva assumida por Merleau-Ponty consiste em compreender que a identificação da consciência à atividade neuronal constitui um equívoco que se torna perceptível "porque rejeitamos o formalismo da consciência e fizemos do corpo o sujeito da percepção" (1999, p. 303). Em suma, a consciência deve ser entendida, antes de tudo, como uma intencionalidade pré-reflexiva atrelada à corporeidade. Esta mesma posição foi sintetizada mais tarde por Francisco Varela, Evan Thompson e Eleanor Rosch no conceito de enativismo e é dele que trataremos na seção seguinte ${ }^{1}$. Antes disso, vejamos, primeiramente, um breve resumo das três principais abordagens da ciência cognitiva.

A preocupação inicial da obra de Varela et al. consiste em propor uma historiografia da ciência cognitiva divida em três estágios de sucessão de paradigmas: cognitivismo, emergentismo (ou conexionismo) e enativismo. O primeiro paradigma provém do trabalho de autores como Chomsky, Newell e Fodor; o segundo, por sua vez, possui Dennett e Hofstadter como principais representantes; por fim, o enativismo surge a partir do trabalho de nomes como Heidegger, Merleau-Ponty, Jean Piaget, Hubert Dreyfus e George Lakoff. Vejamos rapidamente a definição de cada paradigma.

O cognitivismo constitui "o centro ou núcleo da ciência cognitiva" (VARELA et al., 1991, p. 29) e pode ser entendido como o esforço de equiparar a cognição humana a computações representacionais:

1 A obra A Mente corpórea - ciência cognitiva e experiência humana, de Francisco Varela, Evan Thompson e Eleanor Rosch, deixa claro, logo na introdução, a inspiração das ideias contidas em suas páginas: "Gostaríamos de considerar o trabalho desenvolvido ao longo deste livro como uma continuação moderna de um programa de investigação iniciado há mais de uma geração pelo filósofo francês Maurice Merleau-Ponty. Por continuação não queremos dizer uma consideração erudita do pensamento de Merleau-Ponty no contexto da ciência cognitiva contemporânea. Pelo contrário, queremos apenas afirmar que os trabalhos de Merleau-Ponty inspiraram e guiaram o desenvolvimento desta obra". Cf. VARELA, F.; THOMPSON, E.; ROSCHE, E. A Mente corpórea: ciência cognitiva e experiência humana. Lisboa: Instituto Piaget, 1991, pp. 15-16. 
o cognitivismo consiste na hipótese de que a cognição - incluindo a cognição humana - é a manipulação de símbolos nos moldes daquilo que é executado pelos computadores digitais. Por outras palavras, a cognição é uma representação mental: a mente é definida como operando em termos de manipulação de símbolos que representam características do mundo ou representam o mundo como sendo de um determinado modo (VARELA et al., 1991, pp. 30-31).

Por muito tempo o cognitivismo foi praticamente sinônimo de ciência cognitiva, porém, outras abordagens alternativas surgiram para contrapor sua hegemonia, sendo o emergentismo/conexionismo e o enativismo as principais delas. Basicamente, a crítica ao cognitivismo divide-se em duas observações: a) o questionamento se o processamento de símbolos é, de fato, o meio adequado para definir uma representação e b) a crítica à própria "noção de que a cognição é fundamentalmente representação" (VARELA et al., 1991, p. 32). A segunda observação consiste na característica fundamental da abordagem enativista enquanto a primeira provém do conexionismo, que é assim definido:

Esta designação é baseada na ideia de que muitas tarefas cognitivas (tais como a visão ou a memória) aparentam ser executadas de uma melhor forma por sistemas constituídos por muitos componentes simples, os quais, quando ligados por regras apropriadas, dão origem ao comportamento global correspondente à tarefa desejada. O processamento dos símbolos é, porém, localizado. As operações com símbolos podem ser especificadas usando apenas a forma física dos símbolos e não o seu significado [...]. Os modelos conexionistas trocam geralmente o processamento simbólico localizado por operações distribuídas (operações que se estendem por uma rede completa de componentes), resultando, deste modo, na emergência de propriedades globais resilientes ao funcionamento deficiente localizado. Para os conexionistas, uma representação consiste na correspondência entre a emergência de um estado global deste tipo e as propriedades do mundo; não se trata de uma função de símbolos particulares (VARELA et al., 1991, pp. 31-32). 
O enativismo, por sua vez, pretende ultrapassar os dois paradigmas anteriores ao questionar a própria necessidade de assumir a representação como componente central ou primário da cognição:

Propomos como nome o termo enação para salientar a convicção crescente de que a cognição não é a representação de um mundo preestabelecido elaborada por uma mente predefinida, mas é, antes, a atuação de um mundo e de uma mente com base numa história da variedade de ações que um ser executa no mundo (VARELA et al., 1991, p. 32, grifo nosso).

Logo percebe-se a influência de Merleau-Ponty na abordagem enativista quando lembramos de afirmações como as que defendem que "o pensamento objetivo ignora o sujeito da percepção. Isso ocorre porque ele se dá o mundo inteiramente pronto, como meio de todo acontecimento possível, e trata a percepção como um desses acontecimentos" (MERLEAU-PONTY, 1999, p. 279). Em outras palavras, tanto Merleau-Ponty quanto o enativismo de Varela, Thompson e Rosche apontam que o mundo não é um conjunto de inputs previamente dados que seriam internamente representados pelos organismos, pois a cognição funda-se a partir de uma percepção que funciona baseada no a priori da espécie e na história comportamental variável de cada organismo. Em suma, "aquele que sente e o sensível não estão diante do outro como dois termos exteriores, e a sensação não é uma invasão do sensível naquele que sente" (MERLEAU-PONTY, 1999, p. 288), ou seja, a cognição não é a apreensão representacional de um mundo acabado, mas o processo pré-categorial e pré-reflexivo de constituição de contextos.

\section{Enativismo}

A tarefa central que anima o projeto enativista é a de "questionar a ideia de que o mundo tem propriedades preestabelecidas que nós representamos" (VARELA et al., 1991, p. 179). O pressuposto cognitivista de que o mundo não se molda a partir da retroatividade entre organismo e ambiente, ou seja, de que o mundo já é algo dado e que apenas seria representado internamente, é o pressuposto fundamental do tipo de prática em ciência cognitiva que o enativismo visa ultrapassar: "o desafio posto à ciência cognitiva é questionar uma 
das convicções mais arraigadas da nossa herança científica - de que o mundo é independente do sujeito conhecedor" (VARELA et al., 1991, p. 199). Em outras palavras, o enativismo pode ser entendido como a negação da representação de inputs pré-estabelecidos: "aquilo que um ambiente é não pode ser separado daquilo que os organismos são e daquilo que fazem [...] a espécie produz e especifica o seu próprio domínio de problemas a serem resolvidos" (VARELA et al., 1991, p. 258). Dessa forma, as características de um ambiente não são padrões externos identificados e representados por um organismo, mas um domínio específico à cada espécie. $\mathrm{O}$ avanço do conexionismo frente ao cognitivismo significa uma melhoria na compreensão do funcionamento do processamento de informação que se dá na cognição, porém ambas as posições ainda sofrem do pressuposto realista que pensa o mundo como uma configuração rigidamente pré-estabelecida, isto é, o processamento de informação (seja ele pensado de forma cognitivista ou conexionista) continua a pressupor que o Umwelt (UEXKÜLL, 2011) do organismo já se encontra no mundo de forma dada, acabada. Em suma, tanto o cognitivismo quanto o conexionismo pecam em não perceber que, na verdade, a cognição é "a dialética do meio e da ação" (MERLEAU-PONTY, 1999, p. 262):

mesmo quando as próprias ideias de representação e processamento de informação se alteram consideravelmente, como acontece no estudo das redes conexionistas, auto-organização e propriedades emergentes, persiste uma certa forma de assunção realista. No cognitivismo, o realismo é pelo menos explícito e defendido; no entanto, na abordagem da emergência, torna-se frequentemente tácito e inquestionado. Esta postura irrefletida é um dos maiores perigos que enfrenta o campo da ciência cognitiva; limita o leque de teorias e ideias e deste modo impede uma visão mais ampla e um futuro para o campo (VARELA et al., 1991, p. 180).

Portanto, o estabelecimento de um paradigma enativista passa, necessariamente, pelo abandono do pressuposto realista que há nas abordagens conexionista e cognitivista. Tal empreitada requer, antes de tudo, uma revisão da noção de representação assumida por tais paradigmas, pois quando ambos assumem que a representação é "um processo de recuperação ou de reconstrução de características do meio independentes e extrínsecas” (VARELA et al., 1991, p. 183), 
percebe-se aí, então, o que falta à tais posições: a assunção de que a cognição é não a leitura representacional de um ambiente, mas a própria criação de algo que possa ser chamado de ambiente:

É verdade, conforme nota Richard Rorty, que não existe qualquer forma de levantar as questões céticas tradicionais da epistemologia em ciência cognitiva [...] Mas isso não implica, conforme Rorty parece pensar, que a atual concepção naturalizada de representação não tem nada a ver com a imagem tradicional da mente como um espelho da natureza. Pelo contrário, um aspecto crucial desta imagem permanece vivo na ciência cognitiva contemporânea - a ideia de um mundo ou ambiente natural com características extrínsecas e preestabelecidas que são recuperadas através de um processo de representação. Em certos aspectos, o cognitivismo é a afirmação mais forte feita até agora da visão representacional da mente referida pela primeira vez por Descartes e Locke. De fato, Jerry Fodor, um dos expoentes máximos do cognitivismo e um dos mais eloquentes, vai ao ponto de dizer que o único aspecto em que o cognitivismo é um avanço importante sobre o representacionalismo dos séculos XVIII e XIX é o seu uso do computador como um modelo da mente (VARELA et al., 1991, p. 185).

Portanto, uma superação de tal perspectiva significa assumir "a necessidade de compreender os sistemas cognitivos não com base nas suas relações de input e output, mas através do fechamento operacional [operational closure]" (VARELA et al., 1991, p. 187). Um sistema fechado operacionalmente é, para Varela, nada mais que uma organização autopoiética que, por definição, não opera por via representacional, isto é, em vez de representar um mundo, tais sistemas autopoiéticos fazem surgir um mundo. Em suma, "devemos questionar a ideia de que o mundo é preestabelecido e que a cognição é representação" (VARELA et al., 1991, p. 187), ou seja, trata-se de assumir que não há uma fundamentação última por detrás dos fenômenos.

Dessa forma, fica mais claro e fácil definir aquilo ao qual o enativismo contrapõe-se. O contexto de um ambiente durante uma determinada atividade efetuada por um organismo é, na maior parte das vezes, algo que escapa a uma lista finita de dados a serem representados. Tomemos um exemplo no qual a inteligência artificial do programa cognitivista mostrou-se bastante efetiva: o jogo de xadrez. 
O "espaço" e a "finalidade" do xadrez são domínios onde a especificação dos estados possíveis constitui uma tarefa relativamente fácil. Existem as posições no tabuleiro, as regras de movimento para cada peça, o objetivo final do jogo e etc. Por outro lado, se pensarmos em tarefas menos circunscritas ou menos bem definidas, nota-se que tal abordagem se mostra menos eficaz. Por exemplo, na atividade de tocar um instrumento durante uma improvisação de uma banda de jazz: a máquina deve ou não prestar atenção no ambiente no qual a banda se encontra? Faz diferença o número, o gênero ou a etnia das pessoas que estão ouvindo? Faz diferença se há ou não pessoas escutando? É necessário estar completamente atento à cada um dos outros instrumentos em cada fração de segundo? Quando cabe a introdução de notas dissonantes? E por aí vai. O "espaço" e a "finalidade" de uma improvisação dentro de um determinado estilo musical impõe certas limitações a um paradigma representacional. Há um exemplo de Merleau-Ponty na Fenomenologia da percepção no qual descreve a atividade de datilografar como um tipo de intencionalidade não-representacional. Tal exemplo também nos serve para indicar certa dificuldade em determinar quais são ou não os dados relevantes de um contexto para determinada ação ser levada a cabo:

\footnotetext{
Pode-se saber datilografar sem saber indicar onde estão, no teclado, as letras que compõem as palavras. Portanto, saber datilografar não é conhecer a localização de cada letra no teclado, nem mesmo ter adquirido, para cada uma, um reflexo condicionado que ela desencadearia quando se apresenta ao nosso olhar [...] O deslocamento dos seus dedos não é dado ao datilógrafo como um trajeto espacial que se possa descrever (MERLEAU-PONTY, 1999, p. 199-201).
}

Em outras palavras, o enativismo significa uma certa recuperação do conhecimento que tomamos como senso comum: "Torna-se difícil [em atividades como tocar uma música ou digitar em um teclado] reunir um tal conhecimento do senso comum num todo de conhecimento explícito e proposicional, talvez mesmo impossível" (VARELA et al., 1991, p. 196). Não é difícil perceber que "mesmo a mais simples ação cognitiva requer uma quantidade aparentemente infinita de conhecimento, que tomamos como assegurado, mas tem que ser dado de bandeja ao computador" (VARELA et al., 1991, p. 196). Por tal motivo, a ciência cognitiva e a inteligência artificial eventualmente abandonaram a "esperança cognitivista inicial de encontrar um método geral de resolução de problemas" (VARELA et al., 1991, p. 196) em favor de programas que funcionam em âmbitos mais restritos (como jogos de xadrez ou carros automatizados). 
Dessa forma, "tanto no cognitivismo como no conexionismo, a ambiguidade incontrolável do senso comum do meio ambiente é deixada em larga escala na periferia do questionamento" (VARELA et al., 1991, p. 197). Portanto, se a ambiguidade do conhecimento de senso comum - ao que tudo indica - demonstra que no ambiente não há inputs predefinidos, parece irrealizável a tarefa de programá-lo em forma de representações que seriam um espelho da natureza, isto é, pura transposição interna de um mundo preestabelecido:

De fato, se pretendermos recuperar o senso comum, então deveríamos inverter a atitude representacionista, tratando o know-how dependente do contexto não como um artefato residual que pode ser progressivamente eliminado pela descoberta de regras mais sofisticadas, mas, de fato, como a própria essência da cognição criativa (VARELA et al., 1991, p. 197).

Tal cognição criativa deve ser pensada sempre a partir de um saber primariamente corporal que, por sua vez, deve sempre ser entendido levando em conta sua historicidade. Um organismo apreende seu ambiente não apenas a partir de sua configuração biológica, como também do histórico de ações realizadas. Com isso, a percepção é um processo contínuo de ajuste entre ação e Umwelt:

\footnotetext{
Se somos forçados a admitir que a cognição não pode ser convenientemente compreendida sem o senso comum, e de que o senso comum não é outra coisa senão a nossa história corpórea e social, então a conclusão inevitável é que o sujeito conhecedor e o conhecido, a mente e o mundo, estão em relação um com o outro por meio de uma especificação mútua ou co-originação dependente (VARELA et al., 1991, p. 199).
}

Em outras palavras, a ação ou comportamento de um organismo não significa uma resposta posterior à representação de dados preestabelecidos do mundo, mas sim a retroatividade que caracteriza a enação de qualquer sistema de fechamento operacional, isto é, qualquer organização autopoiética. Um sistema autopoiético significa uma determinada organização da matéria que, além de construir uma corporalidade que a distingue do ambiente, possui o necessário à sua auto-reprodução e, com isso, constitui-se como o grau mínimo de atividade perceptiva que possibilita uma interpretação valorativa do ambiente em vista de 
necessidades, ou seja, "uma interpretação no sentido que seleciona ou produz um domínio de significação a partir do pano de fundo do seu meio aleatório" (VARELA et al., 1991, p. 205). Em outras palavras, ação e percepção são duas faces da mesma moeda:

Assim, e para reiterar um dos nossos principais pontos de vista, podemos afirmar que a rede neuronal não funciona como uma rua de sentido único da percepção para a ação. Percepção e ação, sensorium e motorium, encontram-se interligadas na qualidade de padrões sucessivamente emergentes e mutuamente selecionadores (VARELA et al., 1991, p. 215).

Com isso, encontramos nas formulações de Varela et al. um desdobramento da intencionalidade operante que Merleau-Ponty, na Fenomenologia da percepção, associou à motricidade do organismo: "o mundo que percebemos, que normalmente tomamos como certo, é constituído por padrões complexos e delicados de atividade sensoriomotora" (VARELA et al., 1991, p. 216). O papel da motricidade na atividade cognitiva pode ser compreendido a partir da percepção de cores:

\footnotetext{
Há um problema oculto a respeito do ponto de vista objetivista da visão da cor: o objetivista limita-se a assumir que as reflectâncias da superfície deverão ser encontradas num certo mundo preestabelecido que é independente das nossas capacidades perceptuais e cognitivas. Mas como especificar o que representa uma superfície? Como poderemos especificar as suas arestas, os seus limites, a textura e a orientação, a não ser em relação a um sujeito perceptor para quem estas distinções são relevantes? [...] Em outras palavras, esses modelos [representacionais] tratam o sistema visual como se este tivesse sido simplesmente apresentado a um determinado tipo de objetos pré-especificados cujas reflexões terão depois de ser recuperadas [...] Assim, as cores e as superfícies caminham par a par: ambas dependem das nossas capacidades perceptuais corporalizadas (VARELA et al., 1991, p. 219-220).
}

Portanto, a percepção das cores trata-se de um processo que envolve não somente o sistema visual, mas toda a corporeidade de um sistema autopoiético que traz à tona um Umwelt. Não faz sentido falar de cores apenas pelas propriedades físicas, tampouco apenas pela forma que o sistema visual apreende tais 
propriedades; na verdade, a percepção de cores é apenas mais um aspecto de todo um processo global de enação que faz existir superfícies, objetos e texturas para um determinado organismo: "a cor fornece um paradigma de um domínio cognitivo que não é nem preestabelecido nem representado, mas antes experiencial e enativo" (VARELA et al., 1991, p. 225). No entanto, é importante que fique claro que "só pelo fato de a cor não ser preestabelecida, isto não significa que não possa exibir universais ou que não possa prestar-se a uma análise rigorosa pelos diversos ramos da ciência" (VARELA et al., 1991, p. 225), quer dizer, não há um relativismo extremo onde cada organismo individual percebe suas próprias cores, pois em cada espécie há um conjunto de determinações biológicas que tornam possível o estabelecimento de um mundo compartilhado. Com isso, a perspectiva enativista dá continuidade à tarefa de Merleau-Ponty: superar os extremos das posições realista e idealista. A cor não é um dado preestabelecido que seria representado internamente, como também não é uma mera "reflexão de leis internas do sistema [do organismo]" (VARELA et al., 1991, p. 225); a cognição é, na verdade, uma retroatividade na qual Umwelt e organismo "se especificam uns aos outros" (VARELA et al., 1991, p. 226):

\footnotetext{
Estes dois extremos assumem ambos a representação como sua noção central: no primeiro caso [realismo], a representação é utilizada para recuperar aquilo que é exterior; no segundo caso [idealismo], é utilizada para projetar tudo aquilo que é interior. A nossa intenção é ultrapassar esta lógica geográfica de interior versus exterior, estudando a cognição não como recuperação ou projeção, mas como ação corporalizada (VARELA et al., 1991, p. 226).
}

Ao definir a cognição como ação corporalizada, Varela et al. pretendem destacar dois pontos. Primeiro, a cognição surge a partir de uma base sensoriomotora que está inserida nas esferas ecológica, psicológica e cultural; em segundo lugar, "os processos sensórios e motores, percepção e ação, são fundamentalmente inseparáveis na cognição vivida" (VARELA et al., 1991, p. 226), ou seja, há uma retroatividade entre perceber e agir no mundo, isto é, o agir fundamenta o perceber do mesmo modo que o perceber fundamenta o agir. Além disso, Varela et al. ainda apontam uma conexão evolucionária entre os dois pontos: "Na realidade, [a percepção e a ação] não se encontram ligados de um modo meramente contingente nos indivíduos; também evoluíram em conjunto" (VARELA et al., 1991, p. 226). Dessa forma, chega-se à síntese do que é o enativismo em dois princípios: 
Em poucas palavras, a abordagem da enação é constituída por dois pontos: 1) A percepção consiste numa ação guiada perceptualmente; e 2) As estruturas cognitivas emergem de padrões sensoriomotores recorrentes que permitem que a ação seja guiada perceptualmente (VARELA et al., 1991, pp. 226-227).

Com isso, o foco de investigação enativista deixa de ser o modo como se dá a representação de propriedades de um mundo preestabelecido e passa a ser a compreensão da "estrutura sensoriomotora do sujeito perceptor (o modo como o sistema nervoso estabelece ligações entre superfícies sensórias e motoras)" (VARELA et al., 1991, p. 227), pois é a partir da corporeidade do organismo que se pode determinar "o modo como o sujeito perceptor pode agir e ser moldado pelos acontecimentos do meio ambiente" (VARELA et al., 1991, p. 227). Dessa forma, pode-se perceber claramente a continuidade do pensamento de Merleau-Ponty na perspectiva enativista, algo que já fora assumido por Varela et al. e é mais uma vez reafirmada na passagem seguinte:

Deste modo, a preocupação global de uma abordagem enativista à percepção não é determinar o modo como um mundo independente do sujeito perceptor pode ser recuperado; é, pelo contrário, determinar os princípios comuns ou as ligações à base de leis entre os sistemas sensórios e motores que explicam o modo como a ação pode ser perceptualmente guiada num mundo dependente do sujeito perceptor. Esta abordagem à percepção encontrava-se de fato entre as descobertas centrais da análise conduzida por Merleau-Ponty no seu trabalho inicial. [...] Temos então que, numa tal abordagem, a percepção não se encontra simplesmente mergulhada e limitada pelo mundo que a rodeia; também contribui para a enação deste mundo envolvente. Assim, e conforme Merleau-Ponty observa, o organismo inicia e simultaneamente é moldado pelo ambiente. Merleau-Ponty reconheceu claramente, então, que devemos ver o organismo e o ambiente como mutuamente ligados numa especificação e seleção recíprocas (VARELA et al., 1991, pp. 227-228). 
Para demonstrar esta reciprocidade entre elementos do ambiente e ação guiada perceptualmente (ou seja, a definição enativista de cognição), Varela et al. citam o clássico estudo de Held e Hein (1958) no qual filhotes de gatos criados em completa escuridão desde o nascimento serviram como objeto de estudo. A eventual exposição dos gatos à luz se deu com dois grupos diferentes: "a um primeiro grupo de animais foi permitido mover-se normalmente, mas cada um deles tinha atrelado um simples carro com um cesto que continha um membro do segundo grupo de animais" (VARELA et al., 1991, p. 228). Com isso, apesar de ambos os grupos compartilharem a mesma experiência visual, o segundo grupo teve a apreensão sensório motora subtraída, trazendo evidências claras para a definição da percepção visual normal como uma ação guiada perceptualmente:

\footnotetext{
Quando os animais foram libertados ao fim de algumas semanas deste tratamento, o primeiro grupo de gatinhos comportou-se normalmente, mas aqueles que tinham sido transportados nos cestos comportaram-se como se fossem cegos: esbarravam contra os objetos e caíam continuamente. Este belo estudo defende a visão da enação de que os objetos não são vistos por intermédio da extração visual de características, mas, antes, pela orientação visual da ação (VARELA et al., 1991, p. 229).
}

Por fim, Varela et al. apontam um autor que, a seu modo, defende uma perspectiva enativista como paradigma para a ciência cognitiva em um domínio mais pragmático. Trata-se da perspectiva da robótica baseada no comportamento (behavioral based robotics) de Rodney Brooks (1991), ex-diretor do laboratório de inteligência artificial do MIT. Assim como Varela et al., Brooks defende que o maior equívoco do programa cognitivista foi o de definir o comportamento inteligente partindo da representação como unidade primária de sistemas cognitivos. Brooks, portanto, defende um programa de robótica onde não há a construção de modelos pré-definidos do mundo, ou seja, um robô deve ser apenas munido de sensores que possibilitam a apreensão e enação de objetos, superfícies e etc. Dessa forma, para colocarmos nos termos de Varela et al., é a partir da história de acoplamento do robô e do ambiente que o processo enativo de cognição pode ocorrer. O próprio Brooks admite que sua perspectiva constitui uma aproximação da realidade biológica de organismos, aproximando-o tanto do conexionismo como do enativismo, porém, assim como o conexionismo pode ser visto como uma evolução do cognitivismo, Varela et al. defendem que o programa enativista configura-se como a perspectiva ideal em ciência cognitiva: 


\begin{abstract}
Evidentemente que é sempre possível definir um domínio fixo no âmbito do qual um sistema conexionista possa funcionar, mas esta abordagem obscurece as soluções mais profundas sobre a corporalidade biológica da cognição que se encontram tão próximas do âmbito do programa enativista. Assim, do mesmo modo como o conexionismo se desenvolveu a partir do cognitivismo, inspirado num contato mais próximo com o cérebro, o programa do enativismo dá um passo à frente na mesma direção para abarcar a temporalidade da cognição enquanto história vivida, vista ao nível do indivíduo (ontogenia), da espécie (evolução), ou de padrões sociais (cultura) (VARELA et al., 1991, p. 276).
\end{abstract}

\title{
III. Conclusão
}

O paradigma enativista constitui-se como uma abordagem em ciências cognitivas que visa ultrapassar a ideia de representação como aspecto fundamental da cognição de sistemas autopoiéticos. Nosso intuito foi o de examinar a crítica enativista tanto ao cognitivismo como ao conexionismo, além de demonstrar as raízes do enativismo que residem na obra de Merleau-Ponty.

Recebido em: 27.07.2018 | Aprovado em: 02.10.2018 $R$ Referência Bibliográfica

BROOKS, R. A. Intelligence without representation. Artificial intelligence, v. 47, n. 1-3, p. 139-159, 1991.

CHEMERO, A.; KAUFER, S. Phenomenology: an introduction. Cambridge: Polity Press, 2015.

DREYFUS, H. L. What computers still can't do: a critique of artificial reason. Cambridge: MIT Press, 1992.

HELD, R.; HEIN, A. V. Adaptation of disarranged handeye coordination contingent upon re-afferent stimulation. Perceptual and Motor Skills, v. 8, n. 3, p. 87-90, 1958.
MERLEAU-PONTY, M. A Estrutura do Comportamento. São Paulo: Martins Fontes, 2006. Fenomenologia da Percepção. São Paulo: Martins Fontes, 1999. Résumés de cours. Collège de France (1952-1960), Paris: Gallimard, 1968.

THOMPSON, E. Mind in life: biology, phenomenology and the sciences of mind. Cambridge: Harvard University Press, 2007. 
humans: with a theory of meaning. Minneapolis: University of Minnesota Press, 2011.

VARELA, F; WEBER, A. Life after Kant: natural purposes and the autopoietic foundations of biological individuality. Phenomenology and the Cognitive Sciences. V 1, n 2, pp. 97-125, 2002.

.; THOMPSON, E.; ROSCH, E. A mente corpórea: ciência cognitiva e experiência humana. Lisboa: Instituto Piaget, 1991. 